\title{
Os Modos Não Formais de Expressão da Vontade da Administração
}

\author{
Charles Debbash
}

\begin{abstract}
A
vontade da administração deve inserir-se em formas predeterminadas. Esta regra de ouro do direito administrativo oue é perfeitamente ilustrada por um dos fundamentos do recurso por excesso de poder: o vício da forma, não deve, desde logo, levar à conclusão de que não podem existir modos não formais de expressão da vontade da administração? Tal opinião parece estar de acôrdo com os principios dominantes do direito administrativo. A exigência de forma deve, com efeito, permitir, proteger os cidadãos contra todo arbitrio administrativo. A maior parte das formas são instituidas no interêsse dos administrados. As formas são igualmente destinadas a assegurar o bom funcionamento da máquina administrativa e a garantir a administração contra seus próprios excessos.
\end{abstract}

Essa convergência suscita uma primeira concepção do modo não formal da expressão da vontade da administração. Tratarse-ia de tôda expressão da vontade da administração, envolvendo vício de forma que a tornasse suscetivel de anulação através do recurso por excesso de poder. O modo não formal da expressão da vontade da administração resultaria da patologia do direito administrativo. Semelhante concepção teria a vantagem de tornar o modo não formal perfeitamente identificável. Todos os manuais e repertórios de jurisprudência registram com minúcia os casos de vício de forma. Uma rápida olhadela no repertório Lebon permite localizar os diferentes tipos de vícios de forma. Esta concepção puramente contenciosa de modo não formal parece, entretanto, insuficiente. Como muitas outras noções de direito administrativo baseadas, apenas, no estado da jurisprudência ela não permite discernir senão os modos não formais proibidos, embora existam, na ação administrativa, modos não formais autorizados, tolerados ou, em todo caso, práticos. Por outro lado, o vício de forma adquiriu na terminologia do direito administrativo uma acepção restritiva que não nos permite encará-lo como a antitese do modo formal da expressão da vontade 
da administração. No contencioso administrativo formas são as etapas a serem obedecidas na formação de ato juridico perfeito, como v.g., a consulta a uma comissão, a audiência das pessoas interessadas na decisão a ser tomada. No vício de forma o caráter não formal encontra-se nas preliminares de um ato em si mesmo formalizado.

Quando diz respeito à manifestação exterior da vontade da administração e não mais ao procedimento que a antecede (e é a esta concepção do modo não formal que vamos nos ater), a regra parece ser a ausência de formalismo. Uma vez que o interêsse geral está em jôgo, a vontade da administração deve poder produzir pleno efeito, qualquer que seja a forma sob a qual se manifesta. A ação administrativa implica o recurso a um grande número de atos administrativos. Seria inútil paralisar a administração por causa de numerosas exigências de forma. Anular um ato administrativo por que sua manifestação exterior padece de vício não produziria outro resultado senão o de retardar o funcionamento da máquina administrativa, ficando a administração com a liberdade de refazer seu ato retificando-lhe a forma. A vontade da administração deve, pois, produzir pleno efeito. A opção contenciosa do direito administrativo favorece certa inclinação em face dos modos não formais de expressão da vontade da administração. O processo administrativo contencioso reconhece ao Juiz um poder inquisitorial: o de pesquisar a vontade real da administração apesar de sua manifestação não formal. Pode, assim, o Juiz salvaguardar o interêsse geral por uma interpretação construtiva da vontade da administração. Pode, igualmente, proteger os interêsses particulares fundamentais, mediante a descoberta de objetivos ilegais visados pela administração, ainda que os mesmos não transpareçam, formalmente, num ato administrativo.

Isso explica a grande importância que se reserva no direito administrativo francês aos modos não formais de expressão da vontade da administração, quer quando o Poder Público age, quer quando êle se mantém inerte.

\section{I - OS MODOS NÃO FORMAIS DE EXPRESSÃO DA VONTADE E A INÉRCIA DA ADMINISTRAÇÃO}

A administração cuida dos interêsses gerais da coletividade. Se ela guarda certo contrôle sôbre a oportunidade das medidas a tomar no exercício dessa função não deve ficar na dependência do contrôle judicial. Torna-se necessário, então, lutar contra a inércia da administração, conferindo uma significação ao seu 
silêncio. (1) $O$ silêncio constitui um modo não formal de যxpressão da vontade da administração que o direito administrativo considera, embora não the atribua sempre a mesma significação.

O adágio "quem cala consente" não parece suscetivel de aplicação geral em direito administrativo. Uma certa lentidão é inerente à ação administrativa. Dar uma significação positiva ao silêncio de administração é, pois, correr o risco de fazer os interêsses privados prevalecerem sôbre o interêsse geral, e obrigar a administração a agir precipitadamente, a fim de que não se possa extrair de seu silêncio conseqüências desfavoráveis ao interêsse geral. Eis por que, em princípio, o silêncio da administração equivale a recusa e só excepcionalmente produz os mesmos efeitos jurídicos de uma aceitação.

\section{O Silêncio-Recusa}

Na prática administrativa, a recusa da administração a uma demanda que lhe seja apresentada raramente é formulada de maneira explicita. $\mathrm{O}$ administrador se abstém de responder uma petição que êle não pode ou não quer satisfazer. Essa atitude se explica pelo cuidado dos funcionários em não deixarem transparecer que agiram sob pressão, e de se consagrarem às ações positivas. Ela é igualmente motivada pelo temor de comprometer-se por escrito que todo funcionário traz dentro de si. Êle receia tomar uma posição definitiva e ser obrigado a revê-la, em virtude de uma intervenção administrativa superior ou de uma pressão politica. Seu desejo é conferir a sua decisão um caráter indefinido para poder modificá-la sem dar a impressão de se desdizer. Enfim, as delongas, as decisões implícitas atrairão o recurso em menor escala do que a decisão formalizada. Pode-se esperar que o postulante se desencoraje e não persevere no seu intento. Essa prática administrativa corresponde aos mais estáveis principios jurídicos. A administração não pode empenhar se contra seus próprios agentes.

Mas se o silêncio da administração não importa em consentimento nem por isso deve êle, necessàriamente, criar o vazio jurídico. O problema do silêncio tem sido pôsto principalmente no dominio do recurso. A ação judicial contra a administração depende da existência de uma decisão administrativa prévia. Não seria, assim, admissivel que a administração por seu silêncio pudesse obstar o recurso. Um principio geral teve origem por iniciativa do legislador. Uma petição submetida à administração considera-se rejeitada desde que nenhuma resposta lhe tenha sido

(1) Gouttenoire - "O Silêncio da Administração", th. Paris, 1932. G. Benezra - "O Silêncio da Administração". Rev. Adm. 1967, p. 540. Montané de la Roque - «A Inércia dos Podêres Públicos», Th. Toulouse, 1948. 
dada no prazo de quatro meses (2). O silêncio da administração equivale então a uma decisão implícita de recusa, ensejando o recurso perante o Juiz administrativo. A teoria do silênciorecusa-implicita foi introduzida no direito positivo pelo art. $7^{\circ}$ do decreto de 2 de novembro de 1864 , a propósito do recurso hierárquico formulado perante os ministros contra decisões de seus subordinados. Em seguida foi estendida pelo art. $3^{\circ}$ da lei de 17 de julho de 1900 , pelo art. 51 da ordenação de 31 de julho de 1964 a todos os casos nos quais uma autoridade administrativa silencia durante quatro meses sôbre uma demanda que lhe tenha sido submetida. O decreto de 30 de setembro de 1953 aplicou a mesma teoria aos recursos de competência dos tribunais administrativos. "O silêncio mantido por mais de quatro meses pela autoridade competente a respeito de uma reclamação equivale a recusa". Após a lei de 7 de junho de 1956 (atualmente decreto de 15 de janeiro de 1965) o principio foi estendido a tôdas as matérias administrativas. (3)

A regra do silêncio - decisão implícita de recusa - pode parecer à primeira vista desfavorável aos interêsses dos administrados. Ela permite, em realidade, preencher o vazio juridico criado pela inércia da administração e formular os recursos que compelirão os funcionários a respeitar o direito. Mais vale um silêncio-recusa que um silêncio-nada. Observar-se-á, além disso, que nalguns casos, a teoria do silêncio-recusa conduzirá diretamente à anulação da decisão implícita: quando a administração deve tomar uma decisão motivada, a decisão implícita será sempre anulada, uma vez que, por definição, ela não é motivada (15 de julho de 1964, Duquerroix, Rec. 424). Entre um silêncio-nada, por mais favorável que seja aos interêsses da administração, e um silêncio-anuência que comprometa sistemàticamente 0 interêsse geral, o silêncio-recusa permite às pessoas lesadas defender ìerante o juiz seus interêsses legítimos.

\section{O Silêncio-Consentimento}

O legislador, nalguns casos, deixou de lado a regra do silêncio-recusa e adotou o princípio do silêncio-consentimento.

(2) Em muitos casos um prazo diferente foi estabelecido. Assim o silêncio de dois meses do Conselho Regional ou da Seção disciplinar do Conselho Nacional da Ordem dos Médicos sôbre um recurso em matéria de inscrição equivale a uma decisão denegatória.

(3) Montané de La Roque - "A Inércia dos Podêres Públicos" Tese, Toulouse, 1948.

(4) Antes da lei de 7 de junho de 1956, a regra do silêncio - decisão implicita de recusa não existia a não ser em casos determinados (20 de abril de 1956, Escola Profissional de Desenho Industrial, rec. 1963, concl. Long). 
Nessas hipóteses que não comportam generalização e devem ser interpretadas restritivamente, teve êle o cuidado de respeitar a liberdade de gestão dos órgãos descentralizados, ou de provocar uma ação rápida por parte da administração nesses dominios essenciais.

\section{O Silêncio-Consentimento Atenuação da Tutela}

A tutela é um limite à liberdade de gestão dos órgãos descentralizados. A necessidade da aprovação prévia pela autoridade subordinante figura entre as manifestações mais enérgicas do poder de tutela. Se o silêncio da autoridade tutora significasse recusa, a liberdade dos órgãos descentralizados seria fortemente reduzida. Assim, em numerosos casos, a evolução no sentido da descentralização tem conduzido ao estabelecimento da regra de que aquêle silêncio deve ser interpretado como consentimento.

Para a tutela sôbre as deliberações dos conselhos municipais, - princípio da aprovação tácita foi adotado desde 1926. O art. 46 do Código de Administração Comunal dispõe: "salvo exceção, as deliberações do Conselho Municipal tornam-se executórias quinze dias após seu depósito na prefeitura ou na subprefeitura". O art. 42 do mesmo código precisa: "Se o prefeito ou subprefeito convocado a aprovar uma deliberação do conselho municipal não torna conhecida sua decisão no prazo de quarenta dias, a contar da data do depósito da deliberação, esta se considera aprovada. As deliberações para cuja aprovação, na forma da lei ou dos regulamentos, fôr exigido ato do ministro competente ou decreto, tornam-se executórias de pleno direito, quando nenhuma decisão é tomada a seu respeito, no prazo de três meses, a partir de seu depósito na prefeitura ou subprefeitura". Disposições análogas regulam a tutela sôbre as deliberações do Conselho Geral. "As deliberações que exigem aprovação por ato ministerial, ou decreto, tornam-se executórias de pleno direito, se nenhuma decisão a seu respeito fôr tomada no prazo de três meses, a partir de seu recebimento pelos ministros interessados". Nas mesmas condições, o decreto de 27 de setembro de 1958, relativo à tutela sôbre as caixas de seguridade social podia prever que na ausência duma decisão ministerial, dentro de um mês, a contar da data na qual o ministro tenha sido chamado a manifestar-se, a decisão do conselho administrativo adquire seu inteiro efeito. (5)

(5) V. por exemplo 19 decembre 1962. Le Thersier, Rec. 696. 


\section{O Silêncio-Consentimento Fator de Aceleração do Processo de Decisão}

Em certas matérias é necessário provocar uma ação rápida da parte da administração, porque as questões que lhe são propostas devem permitir a tomada de medidas favoráveis ao intesêsse geral ou ao exercício normal de certas liberdades. A administração não deve, pois, com sua inércia paralisar tais atividades. É preciso, pois, prever um meio de compelir a administração a agir. A regra do silêncio-consentimento é um meio cominatório destinado a compelir a administração a uma ação rápida, sancionando-se seu atraso pela satisfação dada aos interessados. A complexidade das formalidades da licença de construir, conjugada à inércia administrativa, retardam consideràvelmente as construções novas; então, como o desenvolvimento da construção constitui matéria de interêsse nacional, também o decreto de 26 de agôsto de 1964 previu que todos os serviços autorizados ou comissões chamados a decidir e que não tornem conhecida, no prazo de um mês, a contar da data do recebimento do pedido, sua resposta motivada, consideram-se como estando a favor do mesmo. A decisão em matéria de licença de construir, a título prévio ou a título definitivo, reputa-se convencionada se a autoridade competente solicitada a pronunciar $\sim$ se por carta recomendada com aviso de recepção deixa de notificar sua decisão no prazo de um mês.

Nas mesmas condições a legislação relativa à coordenação dos transportes (art. 11 do decreto de 14 de novembro de 1949) prevê que a tarifa de base determinada pela emprêsa é submetida à aprovação do prefeito do departamento-sede da exploração. Se no prazo de dez dias após essa comunicação o prefeito a ela não se opõe, a tarifa considera-se aprovada. Da mesma maneira as regras relativas a certas ordens profissionais prevêem que na ausência de resposta sôbre um pedido de inscrição, êste, após o decurso de um prazo determinado, reputa-se deferido.

O cuidado atual de acelerar a tomada das decisões na administração deveria conduzir a uma multiplicação dos textos que conferem ao silêncio a fôrça da aprovação.

Em todos os casos nos quais o silêncio tem o valor de consentimento, a decisão implícita decorrente da expiração do prazo confere aos interessados os mesmos beneficios que lhes adviriam de uma decisão explícita. Cria para êles direitos que a admi- 
nistração deve respeitar. (6) Na medida em que os interessados tenham fornecido à administração todos os elementos necessários, considera-se a decisão implícita capaz de derrogar as disposições em vigor. (7) Assim, o Conselho de Estado julgou num caso entre o Ministério da Construção e a Sociedade Dagommer e Baroche, tendo assentado que uma vez que o "dossiê submetido ao acôrdo prévio pela sociedade continha os elementos capazes, pela sua natureza, de mostrar, levada em conta a implantação do projeto, se as prescrições dos regulamentos te urbanismo opunham qualquer obstáculo salvo derrogação à construção. . cabia à administração no curso da instrução da demanda do acôrdo prévio examinar se seria ou não conveniente reconhecer à Sociedade Dagommer e Baroche a derrogação eventualmente necessária; que na ausência total de notificação de uma decisão qualquer de sua parte em resposta à demanda, dever-se-ia reputar a administração como estando de acôrdo com a derrogação de que se trata".

A inércia da administração recebe, assim, em direito administrativo, um sentido jurídico. Com mais forte razão, quando a administração age, um efeito pleno deve ser atribuido a sua vontade, qualquer que seja a forma sob a qual ela se manifesta. (8)

\section{II - OS MODOS NÃO FORMAIS DE EXPRESSÃO DA VONTADE E A AÇÃO DA ADMINISTRAÇÃO}

Desde que a administração denote por sua ação a vontade de se vincular, importa consagrar o primado dessa vontade sôbre sua manifestação exterior. De maneira geral e a menos que um texto explícito disponha em contrário, o ato administrativo é válido, uma vez que a administração tenha querido vincular -se vàlidamente. Essa idéia geral explica a ausência de formalismo do ato administrativo (9) e a pesquisa da vontade administrativa pelo juiz.

(6) 16 de janeiro de 1958, Routière, Rec. 28.

(7) Os interessados devem, entretanto, fornecer à administração os elementos necessários que the permitam pronunciar-se em tempo oportuno. 20 de março de 1959 - Federação Nacional de Empregados e Quadros. D. 1959 p. 597 concl. M. Bernard, 9 de outubro de 1964, Comissário do Govêrno junto à Comissão Regional de Reparação de Guerra de Colmar -

(8) Section 19 de fevereiro de 1965, Rec. 125.

(9) A Técnica do ato tipo (P. Rongere, "O Ato Tipo", 1968, notadamente p. 282 e segs.) não parece constituir um modo não formal de expressão da vontade da administração. $\mathrm{O}$ ato tipo é uma manifestação formalizada da vontade da administração. 


\section{Ausência de formalismo do Ato Administrativo}

Tôda manifestação da vontade administrativa recebe pleno efeito.

O princípio do ato escrito poderia parecer fundamental em direito administrativo. O escrito forma a memória da administração. Permite estabelecer com certeza a vontade administrativa. $O$ ato verbal também desempenha um papel de grande importância na ação administrativa. O administrado, o funcionário subalterno não estão em condições de exigir que a administração formule sempre por escrito seu atos. Se surge uma dificuldade no cumprimento de um acôrdo verbal deve-se-lhe opor o princípio do escrito? Isso não seria equitativo.

Mais e mais se desenvolve uma forma de contato direto entre a administração e os administrados, notadamente por meio do telefone. A existência de um escrito afigura-se, assim, em numerosos casos, um formalismo inútil. Eis por que a validade do ato verbal é reconhecida em direito administrativo. Há numerosos exemplos na jurisprudência. As decisões unilaterais puramente verbais de que o Conselho de Estado tem tomado conhecimento, são tais como o licenciamento dum secretário de Prefeitura (10), a ordem dada por um prefeito para depositar na igreja o corpo de um afogado (11), uma delegação por telefone (12), a decisão do Diretor do Pessoal e da Administração Geral do Ministério da Justiça determinando a um magistrado que cesse suas funções administrativas. (13) Nas mesmas condições o Conselho de Estado admite a existência de contratos verbais. Assim julgou êle que um contrato tendo por objeto confiar a particulares mesmo a execução de serviço público encarregado do repatriamento de refugiados estrangeiros presentes em terri-

(10) 2 de junho de 1938. Castellani - Rec. Lebon, 1938, 505.

(11) 9 de janeiro de 1931. (adel S. 1931. 111.41 - Considerando que a ordem verbal dada pelo prefeito constituia, qualquer que fôsse seu caráter, uma decisão tomada por autoridade administrativa.

(12) 11 de junho de 1948, Sabarot. Rec. 260.

(13) 3 de novembro de 1961, Canet, A.J., 1962 - 11 -315, O Sr. Canet demanda a anulação de uma decisão de 11 de janeiro de 1960 , pela qual o Diretor do Pessoal e da Administração Geral do Ministério da Justiça o intimou verbalmente a cessar suas funções de magistrado encarregado do serviço social, que essa decisão cujos efeitos se prolongaram por um mês e meio não constitui uma simples medida de ordem interior; que assim ao requerente cabia demandar a anulação pela via do recurso por excesso de poder. 
tório francês pode ter forma verbal. (14) Essa forma verbal não é evidentemente válida na hipótese da existência de texto que a proscreva. Disposições legais ou regulamentares podem impor a redação de um texto escrito. (15) A forma escrita é, por exemplo, obrigatória para as transações públicas, cujo montante ultrapasse certas cifras $(200,000$ FN para o Estado). O princípio juridico, entretanto, resguarda a validade do ato verbal, cuja existência pode ser provada por todos os meios. As enunciações de um ato escrito podem, de resto, ser contestadas por todos os meios. O Conselho do Estado, depois de haver afirmado que as enunciações de um ato escrito fazem lei enquanto não declaradas falsas pelo juiz competente, admite, por outro lado, que o ato não faz fé senão na ausência de prova em contrário. (16) Isso é bem demonstrar que a forma exterior do ato administrativo tem pouca importância e que só é determinante a vontade real da administração.

Os erros de forma não impedem a expressão da vontade administrativa. A denominação oficial dos atos administrativos unilaterais (decretos, portarias) pode não ser respeitada. As administrações podem tomar suas decisões, dando-lhes a denominação de aviso (17), de circular (18) ou a forma de uma simples carta. (19) Quando um decreto prevê que uma decisão regulamentar deve ser objeto de portarias ministeriais, o Ministro pode tomar essa decisão com o mesmo valor jurídico, sob a forma de circulares. (20)

No mesmo sentido, o êrro ou omissão nas autenticações não atinge a validade do ato administrativo. (21) Quando a administração deixa de indicar nas autenticações o preenchimento de uma formalidade obrigatória o ato administrativo não é menos válido se resulta da instrução que a formalidade foi devidamente preenchida. O êrro na data não constitui em si mesmo um

(14) 20 de abril de 1956, Berlim, D, 1956, 433 nota de Laubadère.

(15) 25 de fevereiro de 1948, Bloch â Rec. 92.

(16) 4 de março de 1955, Athias, R.D.P. 1955-745 Concl. Jacomet. (17) 28 de março de 1952 . Sociedade Estabelecimentos Riculens, D.
1952 - 454 - nota de Quernonne.

(18) 31 de julho de 1948, Câmara Sindical do Livro do Departamento de Constantine, Rec 364.

(19) 10 de dezembro de 1954, Rec. 661. (20) 30 de março de 1960, Sindicato Nacional dos Médicos Biologistas,
R.D.P., 1960-1057.

(21) 10 de janeiro de $1919-$ Arrighi de Casanova, Rec. 11. 25 de fevereiro de 1955, Racié, Rec. 120. 
vício do ato. (22) A preeminência do fundo sôbre a forma fica assim perfeitamente ilustrada.

\section{PESQUISA DA VONTADE DA ADMINISTRAÇÃO PELO JUIZ}

A pesquisa da intenção real da administração é uma preocupação constante do juiz.

$\mathrm{O}$ poder inquisitorial do juiz explica que êle não se atenha tão-sòmente à expressão formalizada da vontade e procure estabelecer por todos os meios aquilo que a administração quis fazer. Essa pesquisa dissimula muitas vêzes o cuidado do juiz em dar uma interpretação razoável aos atos administrativos. O conselho do Estado, pretendendo descobrir a intenção real da administração, esforça-se no sentido de dar aos atos um conteúdo que permita a defesa do interêsse geral e dos interêsses fundamen tais dos administrados.

No domínio dos atos unilaterais, não obstante a regra segundo a qual as decisões administrativas não têm que ser motivadas, - juiz pesquisa constantemente a intenção da administração. Como disse um comissário do govêrno (23), "a regra de que os atos administrativos não têm que ser motivados suprime, em relação a êles. o vício de forma decorrente da falta de motivo; ela não tem a finalidade nem o efeito de subtrair a administração à obrigação de dar a conhecer ao juiz do excesso de poder os motivos dos atos que perante êle forem questionados".

Dio mesmo modo, o juiz faz com que produza conseqüências juridicas tôda atitude, mesmo implícita, que pareça demonstrar da parte da administração a vontade de se obrigar. Assim, quando a administração, em suas conclusões perante o juiz, rejeita as pretensões do requerente, o Conselho de Estado considera que ela toma uma verdadeira decısão, sem que possa prevalecer-se da falta de um pronunciamento prévio. (24) Igualmente, uma decisão incompativel com um precedente importa na ab-rogação dêste último: a nomeação de nôvo titular para um emprêgo importa na exoneração do antigo titular. (25) A administração pode requerer colaboradores ocasionais do serviço público para alcançar seus objetivos. (26)

Em matéria contratual, o juiz administrativo empreende também a pesquisa da intenção. Sem visar expressamente às

(22) 30 de junho de 1952, Balenciaga, Rec. 340.

(23) Concl. de Letourneur, 28 de maio de 1954. Barel R.D.P., 1954, p. 519 .

(24) 29 de março de 1933. Borrou. Rec. 370.

(25) 30 de novembro de 1946, Faure, S, 1946 - 3.37 nota de Benoit.

(26) 28 de abril de 1938. Comuna de Niliana. Rec. 377. 
regras do Código Civil aplica de fato as regras gerais da interpretação (27) no que se refere mais ao elemento volitivo do que ao conteúdo formal do contrato. Assim o art. 1.156 do Código Civil: "Deve-se nas convenções pesquisar qual foi a intenção comum das partes contratantes ao invés de se prender ao sentido literal dos têrmos" inspira numerosas decisões que invocam "a intenção comum das partes". (28) Do mesmo modo o juiz aplica o princípio segundo o qual "tôdas as cláusulas das convenções se interpretam umas pelas outras, dando-se a cada uma o sentido que resulta do ato inteiro" (art. 1.161, Código Civil (29), a regra segundo a qual "as convenções obrigam não sòmente aquilo que está expresso mais ainda a tudo o que a eqüidade, o uso ou a lei reconhecerem como resultantes da natureza da obrigação. Particularmente significativa é a referência ao uso. Um acórdão refere-se, por exemplo, ao "uso estabelecido em Marselha há dez anos" que "era o de não incluir os referidos fornecimentos entre aquêles que davam lugar à remessa" (30).

$\mathrm{O}$ juiz esforça-se por fazer prevalecer o espirito sôbre a letra do contrato. Face à contradição entre as cláusulas de um contrato, o Conselho de Estado estima que "essa divergência que provém de êrro cometido na redação de um caderno de encargos não tem influência sôbre a situação das usinas, tal como resulta de comum intenção das partes" (31). O Conselho de Estado estatui mesmo contra disposições contratuais expressas, quando as mesmas parecerem contrariar a intenção das partes. (32)

A pesquisa da intenção das partes apresenta todavia caracteres originais em confronto com o direito privado. O Conselho de Estado esforça-se por interpretar o contrato no sentido mais favorável ao interêsse geral, o que vale dizer muitas vêzes, mas não sempre, a favor da administração. Como escreveu o Deão Hauriou: "Uma convenção administrativa é sempre mais ou menos relativa à execução de um serviço público ou de uma (27) De Laubadère - "Traité des Contrats Administratifs", t. II.
Peguignot: "Théorie Générale des Contrats Administratifs". D.C.A. fasciculo
18, 510.

(28) 21 de janeiro de 1944. Rec. 23, 13 de junho de 1945, Gasnot, Rec. 19.

(29) 21 de janeiro de 1944, prècipitado. (30) 11 de julho de 1944, Razimband, Rec. 198. v. igualmente 8 de
julho de 1927, Lecamus, Rec. 765 .

(31) 5 de janeiro de 1951. Comuna d'Esparron, Rec. 3.

(32) 5 de novembro de 1937, Depart. des Côtes du Nord, 1938 III. 46. notas A-H "o meio escolhido pelos signatários da transação não respondeu certas das partes no momento do contrato ater-se a uma estrita aplicação da fórmula de revisão contida no instrumento particular. 
obrigação administrativa... Resulta dessa circunstância que a convenção ainda que sinalagmática não pode ser interpretada com seus elementos, próprios ou se se quiser, que a situação não é dominada exclusivamente pelos têrmos do contrato, mas também pelas exigências do serviço público ou pelas da operação administrativa". (33) Eis por que o juiz administrativo coloca acima das estipulações contratuais tôdas as regras relativas ao bom funcionamento e à continuidade do serviço público. Invocando por ficção a vontade presumida das partes, êle edita, em realidade, obrigação de que algum contratante não havia cogitado. A chamada jurisprudência da imprevisão ilustra de maneira significativa essa atitude jurisprudencial. Diante de uma situação imprevista, o juiz impõe às partes um reajustamento contratual, assegurando a continuidade do serviço público. (34) Na ausência de tôda e qualquer disposição contratual. considera que o poder público não poderia ter transigido sôbre a obrigação de salvaguardar o interêsse geral e que êle possui o poder de inflingir sanções ao contratante privado ( 31 de maio de 1907, Deplanque, D. 1907, 3.81, concl. Romieu). Da mesma forma, quando invoca a vontade das partes de manter o equilibrio financeiro do contrato ou impõe a indenização de encargos imprevistos, o juiz cria, sob a capa da interpretação da vontade das partes, estipulações novas. (35)

(33) Nota ao S. 1915-3-17 sôbre 27 de junho de 1913. Estado c/ville de Toulouse.

(34) 30 de março de 1916. Companhia Geral de Iluminação de Bourdeaux. S. 1916:3.19, nota de Hauriou.

(35) A. de Laubadère, obra cit., tomo II, p. 16.

Charles Debbash - Professor da Faculdade de Direito e Ciências Econômicas de Aix-en-Provence, in «La Revue Administrative» - 125 set./out. de 1968, págs. 555/559. Trad. de Tomás de Vilanova Monteiro Lopes. 